\title{
Spinal Cord Injury without Radiographic Abnormality (SCIWORA): About 3 Cases and Review of the Literature
}

\author{
Sesmat H, Hayoun T*, Bonnet JP, Poli-Mérol ML and Bourelle S \\ Département de Chirurgie Pédiatrique, Hôpital Américain, France
}

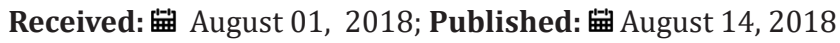

*Corresponding author: Hayoun T, Département de Chirurgie Pédiatrique, Hôpital Américain, 51092 REIMS Cedex, France

\begin{abstract}
Spinal cord injury without radiographic abnormality is a rare and difficult diagnosis. It is a diagnosis of exclusion, without proven effective treatment, with an evolution often unfavorable. We reviewed the literature to learn more about the diagnostic tools and treatment options available. In this study, we report our experience on 3 cases of Spinal cord injury without radiographic abnormality in children aged 1 to 3 years, in the case of road traffic accidents. Today 2 subjects are paraplegic, 1 tetraplegic, all 3 present urinary disorders. We found no diagnostic tool available and feasible in the acute phase of trauma. MRI can be a good way, but it is often unavailable.
\end{abstract}

Keywords: Spinal Cord Injury without Radiographic Abnormality; Spinal Cord Injury; Pediatric Trauma; SCIWORA; Spinal Cord Injury

\section{Introduction}

Spinal cord injury (SCI) is a rare occurrence in children. The injury level varies according to age, cervical injury is more common in younger children. These injuries are different from adult SCI in light of anatomical and biomechanical differences between the spinal cord of children and adults: volume and relative weight of the head, ligamentous laxity and immature cervical muscles. This ligamentous laxity explains the poor radiological semiology found in pediatric SCI. Thus, severe neurological disorders, in the absence of abnormality on standard radiographic imaging, were previously described under the "SCIWORA" syndrome, standing for "Spinal Cord Injury Without Radiographic Abnormality". These traumas in hyperextension, hyperflexion or axis traction lead to transient displacement of the vertebra that gets back into place without bone lesions, while the spinal cord stretched. we report in this article our experience about 3 cases seen in our department between 2001 and 2014

\section{Case Presentation}

Our experience about 3 cases between 2001 and 2014 is summarized in Table 1 . There was no fracture or ligament injury on standard radiographic imaging and CT-Scan performed for all patients [1] (Figure 1).

Table 1: None of these three children received steroids as part of their initial care management.

\begin{tabular}{|c|c|c|c|c|c|c|}
\hline & Age \& Mécanism & Associated lesions & $\begin{array}{c}\text { Clinical } \\
\text { myelopathy }\end{array}$ & $\begin{array}{l}\text { Spinal cord MRI delay } \\
\text { \& results }\end{array}$ & $\begin{array}{l}\text { Spinal cord } \\
\text { angiography }\end{array}$ & Outcome \\
\hline Case 1(2001) & $\begin{array}{c}\text { 1yr: } \\
\text { Strapped in a car } \\
\text { seat \& ejected } \\
\text { during a crash }\end{array}$ & $\begin{array}{c}\bullet \text { Cerebral } \\
\text { hemorrhage \& brain } \\
\text { herniation: } \\
\text { Craniectomy at D4 } \\
\bullet 2 \text { fractures of the } \\
\text { long bones }\end{array}$ & Paraplegia & $\begin{array}{c}\text { D20 post-injury } \\
\text { From C6 to T2: } \\
\text { Spontaneous } \\
\text { hypointense signal \& } \\
\text { Hyperintense signal in } \\
\text { T2 STIR }\end{array}$ & No & $\begin{array}{c}\text { 17yrs: } \\
\bullet \text { Paraplegia T2 } \\
\bullet \text { Neurogenic bladder } \\
\text { (Bladder enlargement \& } \\
\text { Continent cystostomy) }\end{array}$ \\
\hline Case 2 (2002) & $\begin{array}{l}\text { 2yrs3mo: } \\
\text { Strapped in a car } \\
\text { seat, not ejected } \\
\text { during the crash }\end{array}$ & No & Tetraplegia & $\begin{array}{c}\text { D1 post-injury } \\
\text { Spinal cord contusion } \\
\text { at T1, edema C3 to T1, } \\
\text { hypointense T1 signal } \\
\text { and a hyperintense } \mathrm{T} 2 \\
\text { signal }\end{array}$ & No & $\begin{array}{c}\text { 16yrs: } \\
\bullet \text { Tetraplegia } \\
\bullet \text { Neurogenic bladder } \\
\text { (Bladder enlargement \& } \\
\text { Continent cystostomy) } \\
\text { - Anterograde colonic wash- } \\
\text { out enemas }\end{array}$ \\
\hline
\end{tabular}




\begin{tabular}{|c|c|c|c|c|c|c|}
\hline Case 3(2014) & $\begin{array}{c}\text { 3yrs6mo: Frontal } \\
\text { head injury in a } \\
\text { traffic accident }\end{array}$ & $\begin{array}{l}\text { Fracture/dislocation } \\
\text { of the left iliac wing } \\
\text { \& Retroperitoneal } \\
\text { hematoma }\end{array}$ & $\begin{array}{l}\text { D0: Urine } \\
\text { retention } \\
\text { without } \\
\text { neurological } \\
\text { symptoms D1: } \\
\text { Paraplegia }\end{array}$ & $\begin{array}{l}\text { D1 post-injury } \\
\text { Contusion of the spinal } \\
\text { cord T11, suspicion of } \\
\text { arteriovenous fistula } \\
\text { (fig 1) }\end{array}$ & $\begin{array}{c}\text { Anterior } \\
\text { spinal artery } \\
\text { thrombosis }\end{array}$ & $\begin{array}{c}\text { 6yrs: } \\
\bullet \text { Paraplegia } \\
\text { • Neurogenic bladder (self- } \\
\text { catheterization) }\end{array}$ \\
\hline
\end{tabular}

Note: STIR: Short Tau Inversion Recovery.

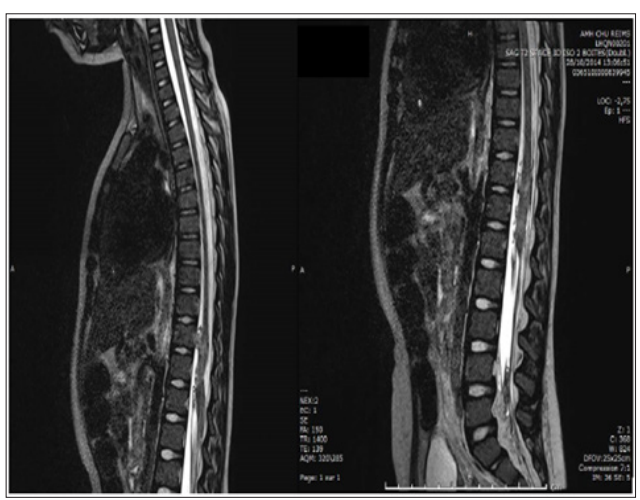

Figure 1: MRI initial case 3: in MRI T2 sequence, hypersignal associated with spinal cord lesion.

\section{Discussion}

The concept of Spinal cord injury without radiographic abnormality was first described in 1982 by Pang and Wilbanger [2]. They precisely defined this syndrome as the onset of clinical

symptoms of myelopathy occurring after trauma in the absence of fracture or spinal cord ligament injury that can be evidenced on standard radiographic imaging and CT-Scan. This definition of SCIWORA excludes injuries from electrical, invasive and obstetrics injuries as well as congenital abnormalities. Most authors agree that clinical symptoms of myelopathy can occur up to 4 days after the trauma [2-4]. SCIWORA is responsible for $6 \%$ to $19 \%$ in children and is highest among children under 8 years of age, who also have the most unfavorable prognosis [5]. In adults there is an equivalence, i.e. "Spinal Cord Injury Without Radiologic Evidence of Trauma" (SCIWORET), in the context of cervical canal stenosis, herniated disk or ankylosing spondylitis, differentiating it from SCIWORA.

Age is a major risk factor for the onset of SCIWORA, children under 8 years old are more exposed, as illustrated by our observations [3]. The most common cause of injury was sport 41 $\%$ followed by motor vehicle collisions as the second $26 \%$ [6-7]. Back bend movements performed during dance practice may cause pediatric thoracic SCIWORA, particularly in children younger than 8 years old [1]. For Pang and Pollack [8], age was also a prognostic factor with more severe lesions seen in children from 0 to 8 . Road traffic accidents are the leading cause of this pathology in young children [6]. Prior reports have demonstrated that SCIWORA in younger children occurs more commonly in the upper cervical spine [6]. The diagnosis of SCIWORA is based on the association of neurological symptoms with a rapid and progressive onset and evidence on MRI imaging. In order to discard with certainty a fracture and ligamentous injury, Pang et Pollack [8] recommended to perform a CT-Scan centered on the level of injury along with dynamic radiographs. Nowdays, MRI became the gold standard in spinal cord injury diagnosis.

It must be scheduled when the patient's clinical picture suggests SCIWORA [9]. Statistical analysis revealed a significant association between the extent of initial neurologic impairment, specific MRI patterns, and subsequent outcome [10]. It is important to examine children in emergencies, especially neurologically, for any child involved in high-energy traumatisms injuries. The onset of a secondary impairment is a telltale sign, even if the impairment is minor. In our third observation, the pelvic fracture complicated our clinical evaluation, but the urinary retention quickly led us to look for signs of impairments. An MRI can validate the diagnosis by refining the injury in terms of level, injury and extension of the lesion. It will show the hemorrhagic or edematous nature of the spinal cord injury. We will observe a low intensity signal on T2-weighted images when there is an acute hemorrhage, a high intensity signal on T2-weighted images for a non-hemorrhagic contusion or ischemia, central areas of low signal intensity, with a peripheral high signal intensity on $\mathrm{T} 2$-weighted images for a hemorrhagic spinal contusion [11].

It brings help to rule out lesions not related to the spinal cord itself such as epidural hematoma, herniated disc or ligamentous tears. It can refine the functional prognosis: a severe or clear spinal cord hematomyelia will carry a more severe prognosis than minor hemorrhage or edema [11-13]. However, in our experience, there was no severe or clear spinal cord hematomyelia, yet there was no functional recovery over time. Thus, if one can confirm the poor prognosis for severe lesions, one cannot guarantee the longterm recovery based on inconclusive imaging results. For several authors, especially Curtis et al [14], angiography and myelography should not be used as diagnostic tools in SCIWORA. However, according to the strict definition of SCIWORA, our 3case described above met all its criteria and an MRI was necessary yet proved insufficient to yield a comprehensive diagnosis for this pathology. As a matter of fact, the angiography, recommended and performed in a specialized center was essential to evidence the anterior spinal artery thrombosis and thus rule out discard the negative evolution of a congenital abnormality, which was the initial diagnosis.

Finally, Pang [2] and Fregeville [11] recommend somatosensory and motor evoked potentials when an MRI is inconclusive. SCIWORA treatment is also being debated. For Pang and Pollack 
[8] a 12-week immobilization is necessary to promote the healing of potential ligamentous lesions and prevent the exacerbation of the myelopathy. The logic behind this treatment option can be argued if one refers to CT-Scan and radiographic results, which by definition must be normal. Thus, this immobilization is useless since there is no evidence of fracture or ligamentous injury. We then do not find the evidence of the relevance of immobilization which is nevertheless recommended in some publications. We did not choose this treatment option in our patients for the abovementioned reasons. Steroid therapy in children is not consensual. Several studies were conducted in adults and today the usual care management in pediatrics stem from the extrapolation of these data. To date, methylprednisolone is the only validated molecule for neuroprotection. Its role consists in stopping the inflammation and reducing lipid peroxidation. However, its use is not risk-free, especially in terms of infections and metabolic disruptions.

In the review of the 2012 literature [15], we found randomized controlled trials in favor of steroid use and others that showed no benefit. Among these 5 studies, 3 found a statistically significant higher risk of complications when using methylprednisolone [16-17]. It showed corticotherapy is useful if begun within 3 to 8 hours after the trauma for a 48 hours duration (16). However, the diagnostic is made with an average of 4 days after the accident. A recent study provides scientific evidence of the harmful effects of this therapy on the spinal tissue [18], nowadays, the use of steroids in children is not recommended. This lack of information justifies conducting new studies on pediatric populations. In current practice, clinicians must maintain a high index of suspicion for occult injury to the spinal cord in children with neurologic deficits after traumatic injury and proceed with advanced neuroimaging for the purpose of improving accuracy of diagnosis and prognosis [17]. The definition of SCIWORA as described in 1982 will certainly evolve since MRI enables to evidence lesions that were not visible in the past. If we strictly look at the definition of spinal cord injury without bone or ligament injury, SCIWORA groups different spinal cord injuries with various etiologies (over-stretching of the spinal cord, hemorrhage, inflammatory edema) among them, as seen in our experience, nutrient artery thrombosis with ischemia. Angiography could be a relevant diagnostic option in the search for an etiology.

\section{Conclusion}

Today, in high-energy traumatic injuries, patients undergo a full body scan in most cases. The absence of spinal cord injury is reassuring but is not incompatible with SCIWORA-related spinal injuries. Poor knowledge of this syndrome can delay the patient's diagnosis, care management and information given to the parents. The differential diagnosis for SCIWORA should systematically be brought up in children in a context of trauma with neurological symptoms, even when these appeared secondarily, and they should be comprehensively screened for. The fundamental diagnostic strategy is now well established with an emergency MRI being routinely done even when standard radiographic and CT-Scan images are normal. However, the therapeutic strategy is not as clearly defined and today, no data from the literature can help establish a care management protocol. Identifying the etiology (thrombosis, edema) could help design a more targeted therapeutic management according to the underlying mechanism. Also, we assume, it could in certain cases improve prognosis, which in our experience remains quite grim on a functional level.

\section{References}

1. Ren J, Zeng G, Ma YJ, Chen N, Chen Z, et al. (2017) Pediatric thoracic SCIWORA after back bend during dance practice: a retrospective case series and analysis of trauma mechanisms. Childs Nerv Syst 33(7): 1191-1198.

2. Pang D, Wilberger JE (1982) Spinal cord injury without radiographic abnormalities in children. J Neurosurg 57(1): 114-129.

3. Hamilton MG, Myles ST (1992) Pediatric spinal injury: review of 174 hospital admissions. J Neurosurg 77(5): 700-704.

4. Osenbach RK, Menezes AH (1992) Pediatric spinal cord and vertebral column injury. Neurosurgery 30(3): 385-390.

5. Visish Srinivasan, Andrew Jea (2017) Pediatric Thoracolumbar Spine Trauma. Neurosurg Clin N Am 28(1): 103-114.

6. Knox J (2016) Epidemiology of spinal cord injury without radiographical abnormality in children: a nationwide perspective. J Child Orthop 10: 255-260.

7. Carroll T, Smith CD, Liu X, Bonaventura B, Mann N, et al. (2015) Spinal cord injuries without radiologic abnormality in children: a systematic review. Spinal Cord 53(12): 842-848.

8. Pang D, Pollack IF (1989) Spinal cord injury without radiographic abnormality in children--the SCIWORA syndrome. J Trauma 29(5): 654664.

9. Dreizin D, Kim W, Kim JS, Boscak AR, Bodanapally UK, et al. (2015) Will the Real SCIWORA Please Stand Up? Exploring Clinicoradiologic Mismatch in ClosedSpinal Cord Injuries. Am J Roentgenol 205(4): 853860.

10. Boese CK, Oppermann J, Siewe J, Eysel P, Scheyerer MJ, et al. (2015) Spinal cord injury without radiologic abnormality in children: a systematic review and meta-analysis. J Trauma Acute Care Surg 78(4): 874-882.

11. Fregeville A, Dumas de la Roque A, De Laveaucoupet J, Mordefroid M, Gajdos V, et al. (2007) Spinal cord injury without radiographic abnormality: review of the literature. J Radiol 88(6): 904-906.

12. Liao CC, Lui TN, Chen LR, Chuang CC, Huang YC (2005) Spinal cord injury without radiological abnormality in preschool-aged children: correlation of magnetic resonance imaging findings with neurological outcomes. J Neurosurg 103(1): 17-23.

13. Davis PC, Reisner A, Hudgins PA, Davis WE, O’Brien MS (1993) Spinal injuries in children: role of MR. AJNR Am J Neuroradiol 14(3): 607-617.

14. Rozzelle CJ, Aarabi B, Dhall SS, Gelb DE, Hurlbert RJ, et al. (2013) Spinal cord injury without radiographic abnormality? (SCIWORA). Neurosurgery 72(2): 227-233.

15. Pettiford JN, Bikhchandani J, Ostlie DJ, St Peter SD, Sharp RJ, et al. (2012) A review: the role of high dose methylprednisolone in spinal cord trauma in children. Pediatr Surg Int 28(3): 287-294.

16. Bracken MB (2012) Steroids for acute spinal cord injury, Cochrane Database of Systematic Reviews 1: CD001046.

17. Caitlin A Farrell, Megan Hannon, Lois K Lee (2017) Pediatric spinal cord injury without radiographic abnormality in the era of advanced imaging. Curr Opin Pediatr 29(3): 286-290.

18. Cabrera Aldana EE, Ruelas F, Aranda C, Rincon Heredia R, Martínez Cruz A, et al. (2017) Methylprednisolone administration following Spinal Cord Injury Reduces Aquaporin 4 expression and exacerbates edema. Mediators Inflamm 4792932. 


\section{ISSN: 2574-1241}

DOI: $10.26717 / B J S T R .2018 .08 .001584$

Hayoun T. Biomed J Sci \& Tech Res

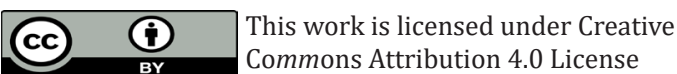

Submission Link: https://biomedres.us/submit-manuscript.php

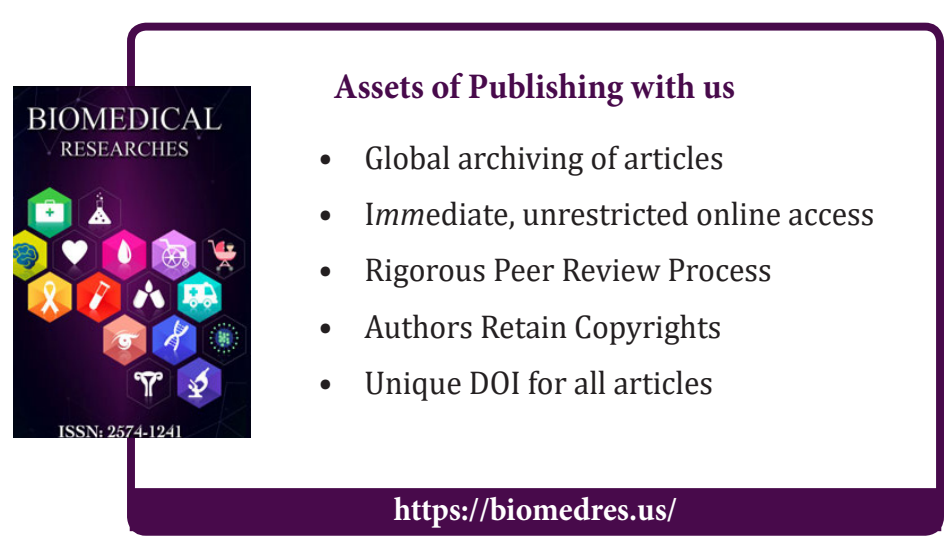

